\title{
BMJ Open Health profile of residents of retirement villages in Auckland, New Zealand: findings from a cross-sectional survey with health assessment
}

\author{
Joanna B Broad (D) , ${ }^{1}$ Zhenqiang Wu, ${ }^{1}$ Katherine Bloomfield, ${ }^{1,2}$ Joanna Hikaka, ${ }^{3}$ \\ Dale Bramley, ${ }^{4}$ Michal Boyd, ${ }^{2,5}$ Annie Tatton, ${ }^{2}$ Cheryl Calvert, ${ }^{6}$ Kathy Peri, ${ }^{5}$ \\ Ann-Marie Higgins, ${ }^{1}$ Martin J Connolly ${ }^{1,2}$
}

To cite: Broad JB, Wu Z, Bloomfield $\mathrm{K}$, et al. Health profile of residents of retirement villages in Auckland, New Zealand: findings from a cross-sectional survey with health assessment. BMJ Open 2020;10:e035876. doi:10.1136/ bmjopen-2019-035876

- Prepublication history and additional material for this paper is available online. To view these files, please visit the journal online (http://dx.doi.org/10. 1136/bmjopen-2019-035876).

Received 04 December 2019 Revised 20 July 2020 Accepted 05 August 2020
Check for updates

(C) Author(s) (or their employer(s)) 2020. Re-use permitted under CC BY-NC. No commercial re-use. See rights and permissions. Published by BMJ.

For numbered affiliations see end of article.

Correspondence to Dr Joanna B Broad; j.broad@auckland.ac.nz

\section{ABSTRACT}

Objectives Retirement villages (RV) have expanded rapidly, now housing perhaps one in eight people aged $75+$ years in New Zealand. Health service initiatives might better support residents and offer cost advantages, but little is known of resident demographics, health status or needs. This study describes village residents-their demographics, socio-behavioural and health statusnoting differences between participants who volunteered and those who were sampled.

Design Cross-sectional study of village residents. The cohort formed will also be used for a longitudinal study and a randomised controlled trial. Village managers (sometimes after consulting residents) decided if representative sampling could be undertaken in each village. Where sampling was not approved, volunteers were sought.

Setting 33 RV were included from a total of 65 villages in Auckland, New Zealand.

Participants Residents $(n=578)$ were recruited either by sampling $(n=217)$ or as volunteers $(n=361)$ during 2016-2018. Each completed a survey and an International Resident Assessment Instrument (interRAl) health needs assessment with a gerontology nurse specialist.

Results Median age of residents was 82 years, 158 (27\%) were men; $61 \%$ lived alone. Downsizing $(77 \%)$, less stress $(63 \%)$ and access to healthcare assistance $(61 \%)$ were most common reasons for entry. During the 2 weeks prior to survey, $34 \%$ received home supports and $10 \%$ personal care. Hypertension, heart disease, arthritis and pain were reported by over $40 \%$. Most common unmet needs related to managing cardiorespiratory symptoms $(50 \%)$ and pain $(48 \%)$. Volunteers and sampled residents differed significantly, mainly in socio-behavioural respects.

Conclusions Common conditions including hypertension, arthritis and atrial fibrillation, are recorded in interRAl as text, and thus overlooked in interRAl reports. Levels of unmet need indicate opportunities to improve health services to better manage chronic conditions. Healthcare service providers and village operators could cooperate to design and test service initiatives that better meet residents' needs and offer cost benefits.

Trial registration number ACTRN12616000685415.
Strengths and limitations of this study

- A customised survey and health needs assessments were conducted by gerontology nurse specialists (GNS) experienced using International Resident Assessment Instrument tools and in assessing the health and related needs of older people.

- Where villages did not permit random selection to obtain a representative sample, volunteers responded to village-wide invitations to participate.

- 578 residents (361 sampled and 217 volunteers) were recruited from 33 retirement villages in a defined geographical area, the largest known survey of village residents in New Zealand (NZ).

- If the GNS had any question about a resident's cognitive capacity to consent, participation was precluded, in compliance with NZ regulations; results will therefore overstate measures of capacity slightly.

- The study establishes a cohort for a longitudinal cohort study of healthcare utilisation, and also a randomised controlled trial of a health service intervention.

\section{INTRODUCTION}

Major changes in housing in New Zealand (NZ) in recent years have included widespread expansion of retirement villages (RV), known elsewhere as continuing care retirement communities. Until the 1980s, housing in NZ was almost entirely detached bungalows. By 2017, RV housed an estimated 13\% of the total NZ population aged over 75 years, $16 \%$ in the Auckland region. ${ }^{1}$ Continued growth in the sector has pleased share market investors, developers and village operators, and most, though not all, of their residents. ${ }^{2}$ RV vary internationally ${ }^{4}$; to clarify their operations in $\mathrm{NZ}$, supplementary materials are available in online supplemental file 1.

In general, studies have shown that residents and their families are attracted to 
the purposefully designed buildings, social and lifestyle opportunities, physical activities and secure environment. ${ }^{56}$ Although health tends to improve following relocation to a village ${ }^{78}$ new and potential residents anticipate support will be available should their health or function decline. ${ }^{6}$ In preparatory work for this study, village residents' health-related needs were intermediate between those of community dwellers and residents in long-term residential care facilities. ${ }^{9}$ Given their greater dependency versus those living in private dwellings, they represent a potentially more vulnerable group. However, little is known about the social/health/dependency characteristics and needs of NZ's village residents or whether support is adequate.

The information that does exist about residents is predominantly from three sources: the industry's own annual reports, ${ }^{10-13}$ the Retirement Commissioner's oneoff survey, ${ }^{6}$ a few qualitative studies ${ }^{14} 15$ and occasional surveys of one/few villages. ${ }^{16}$ Neither the national census nor national health datasets can report demographic or health characteristics of those living in RV. Unlike longterm care facilities, RV are not seen as part of the health system and there is no involvement of health authorities in their operations except where residents receive homebased supports in the same way as they might if living independently. Consequently, no official statistics characterise the demographics, health or unmet health needs of this large group of older people.

Previous studies showed that NZ's RV residents were older, more educated, have more financial resources but significantly greater dependency than those in private dwellings..$^{9} 17^{18}$ Given their greater dependency, they represent a potentially more vulnerable group in terms of transition to long-term care facilities and to acute hospitalisation/death. Improved understandings of the medical acuity of residents could inform health planning to improve quality of life, facilitate independence and reduce service demand. This report describes the social, health status and functional needs of current residents to meet that knowledge gap. It also notes differences between survey participants who volunteered and those who were sampled. The survey is the first part of a larger project with additional objectives: to include the surveyed residents as a cohort in order to describe ongoing health service use and outcomes and identify related factors, and, in residents selected with high needs, to test the effect of a multidisciplinary intervention on health outcomes in a randomised controlled trial (RCT) ${ }^{19}$ Results of these latter two parts will be reported separately.

\section{METHODS}

\section{Eligibility and recruitment}

Of all 65 villages in two district health board regions (Auckland and Waitematā), 53 were approached. We aimed to recruit a representative sample of 572 residents from all villages, sufficient to power the cohort study and RCT. ${ }^{19}$ The original plan was to enrol residents from a random sample of units in each village. When this proved impracticable, recruitment methods were extended to include volunteers. Two distinct recruitment methods were thus employed:

- Sampled gerontology nurse specialist (GNS) researchers approached randomly selected units (or, in villages with under 60 units, all units) by letter and door-knock/phone; all occupants in selected units were invited.

- Volunteers all residents were invited to participate via newsletters, posters and at resident meetings, but were not door-knocked/phoned.

Sample size for the survey (phase 1) was governed by the number needed for the RCT which followed this study and is not reported here. For the precision of survey estimates, if the prevalence of a characteristic of interest is around $50 \%$ and representative sampling been achieved, the sample $(\mathrm{n}=578)$ would provide at least $4.5 \%$ precision $(50 \% \pm 4.5 \%)$ at a $95 \%$ confidence level.

Any resident who might have diminished capacity to consent was excluded as required under NZ's Code of Health and Disability Services Consumers' Rights. ${ }^{20} \mathrm{~A}$ low threshold for exclusion was applied: Addenbrookes Cognitive Examination Revised score under 65, or that in the opinion of our research GNSs, general practitioner or retirement village manager, the resident might lack capacity, meant the resident was excluded from participation.

\section{Patient and public involvement}

Prior to commencement, pilot projects had explored the design and content of the survey with residents of other villages. ${ }^{9}$ Village managers and in most villages, interested residents, had an opportunity to discuss the study with the GNSs prior to undertaking to participate. A short summary of very preliminary findings, with acknowledgement and thanks for their participation, has been distributed to all participants. A second round of contact with the residents involved with the trial is currently underway. At study end we will provide a report for participating villages, and will invite them to hold meetings for their residents at which study investigators will explain study findings and facilitate discussion about their implications.

\section{Instruments}

Each participant completed a custom-designed resident survey, facilitated by a project GNS. Topics covered reasons for moving into the village, measures of satisfaction and social function. The survey was followed by a health needs assessment of health status, function and dependency. For this assessment we used the internationally recognised interRAI (International Resident Assessment Instrument) suite of tools, ${ }^{21}$ validated to comprehensively assess multiple health, functional and social domains including social and physical health, functional ability, existing supports, diagnoses/conditions, treatment and unmet needs. 
In part, interRAI was chosen because in NZ an interRAI needs assessment is required when older people seek government financial assistance for support services. ${ }^{22}$ We selected the interRAI Community Health Assessment (CHA) instrument because, for those who are well and independent, it includes core items only; when screening questions suggest poorer function one of four supplements is triggered to obtain more detailed information, for example, if greater dependency seems apparent, the Functional Supplement is triggered. ${ }^{23}$ Where a prior interRAI assessment-either HC (Home Care) or LTCF (Long Term Care Facilities) instrument-had been undertaken within the previous 6 months and no major medical or social change had occurred, the prior assessment was used. Prior interRAI assessments are carried forward to the next assessment unless revised by the assessor.

Validated interRAI scales, for example for pain, deaf/ blind, depression, activities of daily living (ADLs) and instrumental activities of daily living (IADLs), indicate particular functional difficulties or loss. ${ }^{24}$ The ADL Self-Performance Hierarchy scale combines four items reported over a 3-day period: personal hygiene, toilet use, locomotion and eating. The IADL Capacity Hierarchy Scale uses eight items: ordinary housework, shopping, using stairs, meal preparation, transportation, managing finances, managing medications and phone use. Seventeen interRAI Clinical Assessment Protocols (CAPs) indicate unmet needs that impact on quality of life and that would normally be addressed in a care plan. ${ }^{25}$

Medical diagnoses and conditions are captured systematically in interRAI in three ways: (1) a pre-specified list of 14 diseases asked of all respondents, (2) health conditions and symptoms documented with specific interRAI questions for example, acid reflux and (3) other specific diagnoses (eg, Parkinson's disease, multiple sclerosis) by tick box conditional on the Functional Supplement being triggered. Additional diagnoses are recorded as free-text if considered relevant to current ADL status. For this report, we combined the systematically collected diagnoses with free text searches. Acute or temporary diagnoses (eg, pneumonia, fracture) and those effectively covered by CAPs (eg, pain, mood, incontinence) are reported as such, that is, not considered as diagnoses/ conditions.

Sociodemographic data, including age, sex and marital status, were collected systematically including ethnic identity. Ethnicity is classified by priority ordering into Māori, Pacific people, Asian, European and other, under standard NZ reporting (level 1) provisions except that we further divide European into NZ European and Other European.

\section{Data acquisition}

The resident survey was administered using the online platform Qualtrics (XM Institute, Utah) usually with the GNS. InterRAI assessments were also conducted online with the GNS, except that some were recorded on paper copy and later entered into the interRAI online system. interRAI data were supplied to the research team by Central Region TAS (Technical Advisory Services, Wellington) following an approval and anonymisation process. Both datasets contain the National Highway Institute (NHI) unique patient identifier. We ascribed each participant a unique study ID, sent a file containing the study ID and the NHI number to TAS enabling interRAI data to be extracted. Data from the survey and interRAI were then merged using the study ID.

\section{Analyses}

This report presents descriptive results of the survey and health needs assessment, comparing results for volunteers and sampled residents. These comparisons used t-tests, Kruskal-Wallis and $\chi^{2}$ tests of proportion, and where numbers were small, Fisher's exact tests. SAS V.9.4 software (SAS Institute) was used for analysis. Statistically significant differences were assumed when $\mathrm{p}<0.01$ in twotailed tests. When less than $5 \%(\mathrm{n}<29)$ of the data were missing, we used single imputation methods (modes for categorical variables and medians for continuous variables) to avoid 'losing' residents from analyses (online supplemental file 2).

\section{RESULTS}

Between June 2016 and August 2018, 578 residents were surveyed (361 volunteers from 296 units in 27 villages, and 217 residents from 190 sampled units in 11 villages; in 6 villages, both recruitment methods were used). Of the units that were randomly sampled, the response rate was $35 \%$. On average, one unit in five had two occupants, thus the mean occupancy was 1.2 residents. Twelve residents (nine sampled, three volunteer) were excluded because they were regarded as lacking capacity to give informed consent.

The interRAI CHA was used for 565 residents (98\%); $2 \%$ used an interRAI HC completed within the previous 6 months. Of all residents surveyed, $31 \%$ had an interRAI needs assessment some time prior to entry to this study. This closely matches the $29 \%$ who said they recalled being previously assessed by someone from the hospital, district health board (or similar) for needing help with home care (eg, cleaning, shopping) or personal care (eg, dressing, showering).

\section{Demographics}

The median age at survey date was 82 years (IQR 76-87 years), with $82 \%$ aged over 75 years; 158 (27\%) were men; $44 \%$ were widowed $(64 \%$ over 5 years ago, $17 \%<2$ years ago) and $42 \%$ married/partnered (table 1). Over $96 \%$ self-identified as European (411 NZ European, 147 other European), seven self-identified as Māori (1\%). Most $(61 \%)$ lived alone though this differed by recruitment method ( $69 \%$ of sampled residents, $56 \%$ of volunteers, $\mathrm{p}=0.002$, table 1$)$. Generally, residents appeared financially well supported, with $75 \%$ receiving income from 
Table 1 Sociodemographic and behavioural characteristics

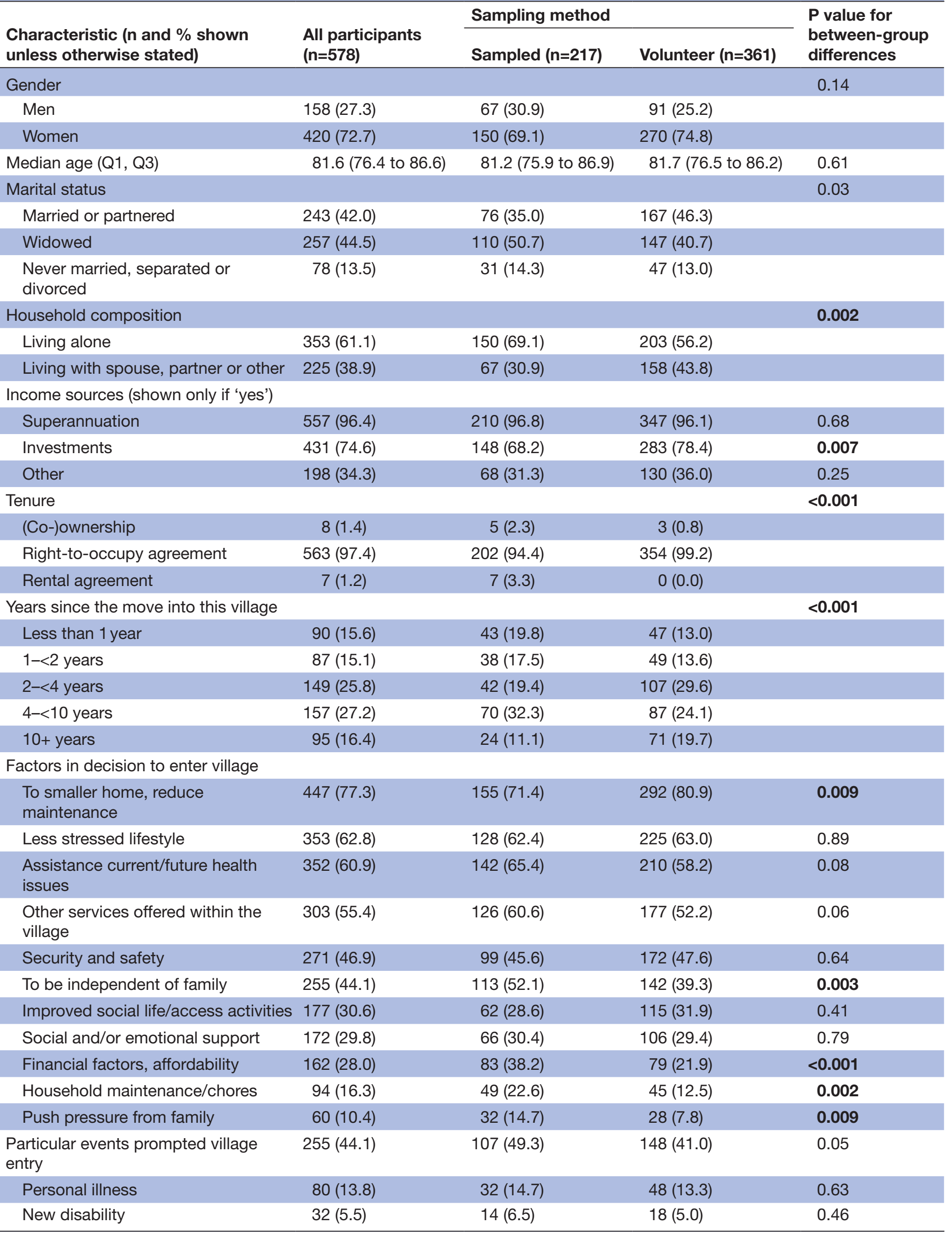


Table 1 Continued

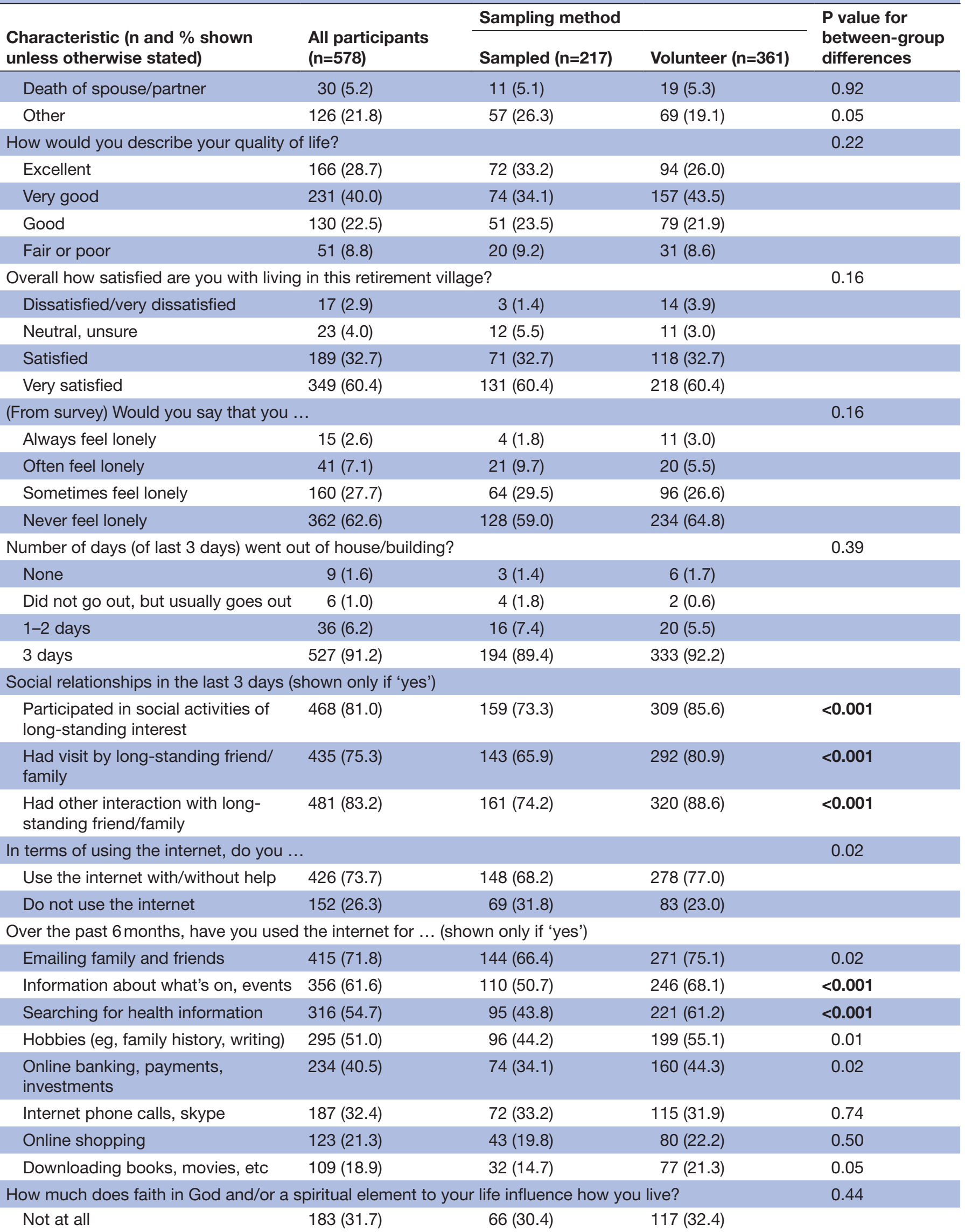


Table 1 Continued

\begin{tabular}{|c|c|c|c|c|}
\hline \multirow{2}{*}{$\begin{array}{l}\text { Characteristic ( } n \text { and \% shown } \\
\text { unless otherwise stated) }\end{array}$} & \multirow{2}{*}{$\begin{array}{l}\text { All participants } \\
(\mathrm{n}=578)\end{array}$} & \multicolumn{2}{|l|}{ Sampling method } & \multirow{2}{*}{$\begin{array}{l}\text { P value for } \\
\text { between-group } \\
\text { differences }\end{array}$} \\
\hline & & Sampled (n=217) & Volunteer $(n=361)$ & \\
\hline Somewhat & $149(25.8)$ & $64(29.5)$ & $85(23.5)$ & \\
\hline Quite a lot & 81 (14.0) & $27(12.4)$ & $54(15.0)$ & \\
\hline Very much & $165(28.5)$ & $60(27.6)$ & $105(29.1)$ & \\
\hline Occasionally & $56(9.7)$ & $13(6.0)$ & 43 (11.9) & \\
\hline Often and regularly & $150(26.0)$ & $60(27.6)$ & 90 (24.9) & \\
\hline
\end{tabular}

Percentages may not total 100 because of rounding. Q1=first quartile, Q3=third quartile.

P-values less than 0.01 are shown in bold.

both investments and National Superannuation; previously, 98\% (co-) owned a home and $91 \%$ were from the Auckland area.

Thirteen residents $(2 \%)$ in a village serviced apartment were being cared for under a government-subsidised aged related residential care contract in which the village provides 24 hours care. All others (98\%) lived 'independently' in terms of decision-making, though some received support services. Tenure was almost entirely by a 'licence to occupy' agreement (99\% among volunteers, $94 \%$ among sampled, $\mathrm{p}<0.001$; table 1 ).

\section{Entry to the village}

The median length of residence was 3.4 years (IQR 1.6-7.1), with $16 \%$ entering within 12 months and a similar proportion more than 10 years previously (table 1 ). The most common reasons for moving to the village were downsizing/reducing home maintenance $(77 \%)$, less stressed lifestyle (63\%), and anticipated better access to assistance with health/care issues $(61 \%)$. Volunteers were more likely to select downsizing ( $81 \%$ vs $71 \%$, $\mathrm{p}=0.009$ ) and less likely to select independence from family (39\% vs $52 \%, \mathrm{p}=0.003)$. For more than one in four residents, particular events prompted the move into the village, including severe personal illness (14\%), onset of a new disability (6\%) and death of a spouse/partner (5\%).

\section{Quality of life, social and lifestyle}

Self-reported quality of life was high, $69 \%$ very good/ excellent (table 1$)$, while most $(93 \%)$ were satisfied/very satisfied with living in the village. $95 \%$ report having a supportive family, $13 \%$ of residents had a pet, and $10 \%$ often/always felt lonely. ${ }^{26}$ Participation in social activities and contact with family was frequent, with $91 \%$ going out of the unit/apartment daily and over $81 \%$ participating in social activities in the past 3 days, but $6 \%$ reported they had no such social contact within the last 3 days.

For 43\%, a faith in God or spiritual aspects of life influenced how they lived quite a lot/very much; $26 \%$ attended church often and regularly. During the previous 90 days, $29 \%$ reported major life stressors (eg, serious illness in self or family member); $10 \%$ reported declining levels of participation in social, religious, occupational or other preferred activities (table 1). Over the previous 6 months $74 \%$ had used the internet, most commonly for emailing $(72 \%)$, finding events of interest $(62 \%)$ and searching health information $(55 \%)$.

\section{Services and support, behaviour, medications}

Demand for formal (paid) support services was clear; during the 2 weeks prior to survey, $34 \%$ received homebased care for household tasks, $10 \%$ personal cares and/ or $7 \%$ nursing care (table 2). In turn, more than half currently provided care for or assisted others, $19 \%$ daily. Less than 2\% smoked tobacco daily and $33 \%$ never drank alcohol, while $29 \%$ had $3+$ hours of physical activity in the last 3 days (table 2).

Several questions inform numbers of medications. The median (IQR) number of different medications taken in the last 24 hours (prescribed or otherwise, as reported in interRAI) was 6 (4.0-8.0). The resident survey separately asked how many prescribed medications were taken 'yesterday' - the median was 5 (3.0-7.0), with $15 \%$ taking 9 or more prescribed medications (table 2 ).

Most participants were active users of health services, with $9 \%$ hospitalised overnight and $94 \%$ seeing a doctor in the past 90 days. (In NZ, a doctor's prescription is normally limited to 3 months' supply). Over the past 12 months, some needed particular health services but did not access them; services most commonly not accessed were dental and audiology (both $4 \%$, table 2).

\section{Functional status, ADLs, IADLs, diagnoses and unmet needs}

Scores on the various interRAI scales indicating risk were low: just $4 \%$ were assessed as borderline intact or mildly impaired on the Cognitive Performance Score $(\geq 1)$ and $4 \%$ indicated as depressed on the Depression Rating Scale (DRS $\geq 3$ ). The Functional Supplement was triggered for $12 \%$ of residents ( $17 \%$ sampled, $8 \%$ of volunteers) (table 2 ).

Residents were assessed as mainly independent in personal hygiene (97\%), walking and locomotion (97\%), for dressing upper and lower body (92\%) and for bathing (90\%); in 
Table 2 Health and lifestyle

\begin{tabular}{|c|c|c|c|c|}
\hline \multirow{2}{*}{$\begin{array}{l}\text { Characteristic } \\
\text { (n and \% shown unless } \\
\text { otherwise stated) }\end{array}$} & \multirow{2}{*}{$\begin{array}{l}\text { All participants } \\
(\mathrm{n}=578)\end{array}$} & \multicolumn{2}{|l|}{ Sampling method } & \multirow{2}{*}{$\begin{array}{l}\mathrm{P} \text { value for } \\
\text { between-group } \\
\text { difference }\end{array}$} \\
\hline & & Sampled $(n=217)$ & Volunteer $(n=361)$ & \\
\hline \multicolumn{4}{|l|}{ Self-rated health } & 0.06 \\
\hline Poor or fair & $131(22.6)$ & $49(22.6)$ & $82(22.8)$ & \\
\hline Good & $387(67.0)$ & $137(63.1)$ & $250(69.3)$ & \\
\hline Excellent & $60(10.4)$ & $31(14.3)$ & $29(8.0)$ & \\
\hline Smokes tobacco daily & $8(1.4)$ & $4(1.8)$ & $4(1.1)$ & 0.48 \\
\hline \multicolumn{4}{|c|}{ Highest number of (alcoholic) drinks in single sitting in last 14 days? } & 0.001 \\
\hline None & $189(32.7)$ & $81(37.3)$ & $108(29.9)$ & \\
\hline One & $266(46.0)$ & $79(36.4)$ & $187(51.8)$ & \\
\hline $2-5$ & $123(21.3)$ & $57(26.3)$ & $66(18.3)$ & \\
\hline \multicolumn{4}{|c|}{ Hours exercise/physical activity in last 3 days } & 0.01 \\
\hline None /less than 1 hour & $253(43.8)$ & $79(36.4)$ & $174(48.2)$ & \\
\hline $1-2$ hours & $165(28.5)$ & $69(31.8)$ & $96(26.6)$ & \\
\hline 3-4 hours & $118(20.4)$ & $45(20.7)$ & $73(20.2)$ & \\
\hline More than 4 hours & $42(7.3)$ & $24(11.1)$ & $18(5.0)$ & \\
\hline \multicolumn{5}{|c|}{ Paid support or services over the past 2 weeks (shown only if 'yes') } \\
\hline $\begin{array}{l}\text { Homecare (eg, cleaning, } \\
\text { laundry, shopping) }\end{array}$ & $198(34.3)$ & $79(36.4)$ & $119(33.0)$ & 0.40 \\
\hline $\begin{array}{l}\text { Personal care (eg, showering, } \\
\text { dressing) }\end{array}$ & $60(10.4)$ & $30(13.8)$ & $30(8.3)$ & 0.04 \\
\hline Nursing or similar services & $39(6.7)$ & $15(6.9)$ & $24(6.6)$ & 0.90 \\
\hline
\end{tabular}

How many prescribed medications did you take yesterday (over a 24 hours period)? (from survey, 42 missing)
Median (Q1, Q3)
5.0 (3.0 to 7.0$)$
5.0 (3.0 to 7.0$)$
5.0 (3.0 to 7.0$)$
0.86

How many active medications in the last 24 hours (incl. non-prescribed, from interRAI)
Median (Q1, Q3)
6.0 (4.0 to 8.0$)$
6.0 (4.0 to 8.0)
$6.0(3.0$ to 8.0$)$
0.67

Health service use with overnight stay in past 90 days (shown only if 'yes')
Inpatient acute care overnight 54 (9.3)
$24(11.1)$
$30(8.3)$
0.28

stay

$\begin{array}{lcccc}\text { Emergency room visit } & 24(4.2) & 7(3.2) & 17(4.7) & 0.38 \\ \text { Physician/GP/NP visit } & 541(93.6) & 200(92.2) & 341(94.5) & 0.28\end{array}$

Needed health services over past 12 months but did not access (shown only if 'yes')

$\begin{array}{llllr}\text { Optician } & 12(2.1) & 10(4.6) & 2(0.6) & 0.001 \\ \text { GP } & 16(2.8) & 11(5.1) & 5(1.4) & 0.01 \\ \text { Audiologist } & 22(3.8) & 13(6.0) & 9(2.5) & 0.04 \\ \text { Dentist } & 24(4.2) & 18(8.3) & 6(1.7) & <0.001\end{array}$

Prevention, monitoring (shown only if 'yes')

\begin{tabular}{|c|c|c|c|c|}
\hline $\begin{array}{l}\text { Blood pressure measured in } \\
\text { last year }\end{array}$ & $572(99.0)$ & $214(98.6)$ & $358(99.2)$ & 0.68 \\
\hline Eye exam in last year & $504(87.2)$ & $175(80.6)$ & $329(91.1)$ & $<0.001$ \\
\hline Influenza vaccine in last year & $492(85.1)$ & $178(82.0)$ & $314(87.0)$ & 0.11 \\
\hline Dental exam in last year & $340(58.8)$ & $105(48.4)$ & $235(65.1)$ & $<0.001$ \\
\hline Hearing exam in last 2 years & $314(54.3)$ & $102(47.0)$ & $212(58.7)$ & 0.006 \\
\hline Colonoscopy in last 5 years & $125(21.6)$ & $44(20.3)$ & $81(22.4)$ & 0.54 \\
\hline $\begin{array}{l}\text { Mammogram/breast exam in } \\
\text { last } 2 \text { years (women only) }\end{array}$ & $89(15.4)$ & $45(20.7)$ & $44(12.2)$ & 0.007 \\
\hline
\end{tabular}

Continued 
Table 2 Continued

Characteristic (n and \% shown unless

otherwise stated)

\section{All participants $(\mathrm{n}=578)$}

Sampling method

Sampled $(n=217)$
$P$ value for between-group difference

\section{Self-reported symptoms (shown only if present)}

Fatigue

Minimal

$$
244(42.2)
$$

Moderate or severe

$61(10.5)$

Difficulty falling asleep

Present but not exhibited in last 3 days
Exhibited on one or 2 of last 3 days

Exhibited daily in last 3 days 115 (19.9)

Dyspnoea, shortness of breath present

$\begin{array}{lc}\begin{array}{l}\text { Absent at rest, present in } \\ \text { moderate activities }\end{array} & 130(22.5) \\ \begin{array}{l}\text { Absent at rest, present in } \\ \text { normal activities }\end{array} & 48(8.3) \\ \text { Present at rest } & 10(1.7)\end{array}$

Bladder incontinence

$\begin{array}{ll}\text { Infrequently incontinent } & 25(4.3) \\ \text { Occasionally incontinent } & 21(3.6) \\ \text { Frequently/always incontinent } & 29(5.0)\end{array}$

\section{Selected interRAI scales}

Deaf/blind severity

24

$\begin{array}{rrr}77(35.5) & 167(46.3) & 0.04 \\ 24(11.0) & 37(10.3) & \\ & & 0.006\end{array}$

\begin{tabular}{|c|c|c|c|c|}
\hline Both senses intact (0) & $288(49.8)$ & $116(53.5)$ & $172(47.6)$ & \\
\hline $\begin{array}{l}\text { One sense intact, one mild/ } \\
\text { moderate impaired (1) }\end{array}$ & $239(41.4)$ & 79 (36.4) & $160(44.3)$ & \\
\hline $\begin{array}{l}\text { Both senses mild/moderately } \\
\text { impaired (3) }\end{array}$ & $42(7.3)$ & $16(7.4)$ & $26(7.2)$ & \\
\hline $\begin{array}{l}\text { One or both senses severely } \\
\text { impaired }(2,4,5)\end{array}$ & $9(1.6)$ & $6(2.8)$ & $3(0.8)$ & \\
\hline Depression Rating Scale & & & & 0.87 \\
\hline $\begin{array}{l}\text { Potential/actual depression } \\
(3-14)\end{array}$ & $23(4.0)$ & $9(4.1)$ & $14(3.9)$ & \\
\hline Functional Supplement triggere & & & & 0.002 \\
\hline Triggered & $67(12 \%)$ & $37(17 \%)$ & $30(8 \%)$ & \\
\hline $\begin{array}{l}\text { IADL Capacity Hierarchy Scale } \\
\text { (range 0-6) }\end{array}$ & & & & 0.001 \\
\hline Supervision required (1) & $134(23.2)$ & $37(17.1)$ & 97 (26.9) & \\
\hline Limited impairment (2) & $93(16.1)$ & $44(20.3)$ & 49 (13.6) & \\
\hline $\begin{array}{l}\text { Extensive assistance needed, } \\
\text { or dependent }(3-6)\end{array}$ & $58(10.0)$ & $26(12.0)$ & $32(8.9)$ & \\
\hline
\end{tabular}

\section{Selected interRAI CAPs indicating unmet need}

\begin{tabular}{|llll}
$\begin{array}{l}\text { Number of CAPs triggered } \\
\text { Median (Q1, Q3) }\end{array} \quad \begin{array}{lll}\text { 3.5 (2.0 to } 5.0) \\
\text { Cardiorespiratory conditions CAP triggered }\end{array}$ & $3.0(2.0$ to 5.0$)$ & $4.0(2.0$ to 5.0$)$ & 0.68 \\
\hline $\begin{array}{l}\text { Triggered (L1) } \\
\text { Pain CAP triggered }\end{array}$ & $109(50.2)$ & $180(49.9)$ & 0.93 \\
\hline
\end{tabular}




\begin{tabular}{|c|c|c|c|c|}
\hline \multirow{2}{*}{$\begin{array}{l}\text { Characteristic } \\
\text { ( } \mathrm{n} \text { and } \% \text { shown unless } \\
\text { otherwise stated) }\end{array}$} & \multirow{2}{*}{$\begin{array}{l}\text { All participants } \\
(\mathrm{n}=578)\end{array}$} & \multicolumn{2}{|l|}{ Sampling method } & \multirow{2}{*}{$\begin{array}{l}P \text { value for } \\
\text { between-group } \\
\text { difference }\end{array}$} \\
\hline & & Sampled $(n=217)$ & Volunteer $(n=361)$ & \\
\hline Medium priority (L1) & $205(35.5)$ & $61(28.1)$ & $144(39.9)$ & \\
\hline High priority (L2) & $75(13.0)$ & $36(16.6)$ & 39 (10.8) & \\
\hline $\begin{array}{l}\text { Physical activities promotion } \\
\text { CAP triggered (L1) }\end{array}$ & 248 (42.9) & $77(35.5)$ & $171(47.4)$ & 0.005 \\
\hline $\begin{array}{l}\text { Informal support CAP triggered } \\
\text { (L1) }\end{array}$ & $200(34.6)$ & $84(38.7)$ & $116(32.1)$ & 0.11 \\
\hline $\begin{array}{l}\text { Social relationship CAP triggered } \\
\text { (L1) }\end{array}$ & $149(25.8)$ & $55(25.3)$ & $94(26.0)$ & 0.85 \\
\hline Mood CAP triggered & & & & 0.50 \\
\hline Medium risk (L1) & $106(18.3)$ & $45(20.7)$ & $61(16.9)$ & \\
\hline High risk (L2) & $23(4.0)$ & $9(4.1)$ & $14(3.9)$ & \\
\hline Urinary incontinence CAP triggere & & & & 0.008 \\
\hline Prevent decline (L2) & $46(8.0)$ & $20(9.2)$ & $26(7.2)$ & \\
\hline Facilitate improvement (L3) & $30(5.2)$ & $19(8.8)$ & $11(3.0)$ & \\
\hline Falls CAP triggered & & & & 0.41 \\
\hline Medium risk (L1) & $54(9.3)$ & $16(7.4)$ & $38(10.5)$ & \\
\hline High risk (L2) & $7(1.2)$ & $3(1.4)$ & $4(1.1)$ & \\
\hline IADL CAP triggered (L1) & $31(5.4)$ & $16(7.4)$ & $15(4.2)$ & 0.10 \\
\hline $\begin{array}{l}\text { Appropriate medications CAP } \\
\text { triggered (L1) }\end{array}$ & $22(3.8)$ & $9(4.1)$ & $13(3.6)$ & 0.74 \\
\hline
\end{tabular}

Percentages may not total 100 because of rounding. Q1=first quartile, Q3=third quartile, L1=Level one low need, L2=Level two moderate need, L3=high need.

$P$-values less than 0.01 are shown in bold.

ADL, activities of daily living; CAP, Clinical Assessment Protocol; GP, general practitioner; IADL, instrumental activities of daily living; interRAI, International Resident Assessment Instrument; NP, nurse practitioner.

combination, $98 \%$ rated as independent on the ADL Hierarchy Scale. For IADL capacity, 53\% reported independence in ordinary housework, and over $80 \%$ in shopping, using stairs, meal preparation, transportation, managing finances, managing medications and phone use. The IADL Capacity Hierarchy Scale ${ }^{24}$ combines these individual components: $10 \%$ needed extensive assistance (table 2).

The most common chronic medical diagnoses were hypertension $(53 \%)$, any heart disease $(46 \%)$, arthritis $(38 \%)$, reflux disorder $(36 \%)$, coronary heart disease $(35 \%)$ and vision/eye disorder (32\%). Multi-morbidity was common, recording a median of 4.0 (IQR 3.0-7.0) conditions; only $2 \%$ gave no current chronic conditions while $9 \%$ reported nine or more.

Unmet needs were also common; $70 \%$ triggered three or more CAPs, most commonly to manage cardiorespiratory indications $(50 \%)$ and pain $(48 \%$, table 2$)$. Figure 1 shows diagnoses with over $5 \%$ prevalence and CAPs.

\section{DISCUSSION}

\section{Resident characteristics}

Resident assessments provide a demographic profile of people of advanced age (median age 82 years) and mainly $(73 \%)$ women. That under $4 \%$ were of Māori, Asian or Pacific ethnicity is at considerable variance to the demographic mix served by the two health board populations, where in 2018, of those aged over 75 years, 80\% were European/other, 3\% were Māori, 13\% Asian and 3\% Pacific peoples (Statistics New Zealand, unpublished data). Residents clearly form a more homogeneous group than is the older population in the region, with less ethnic diversity, greater prior home ownership and more with income sources other than NZ superannuation. ${ }^{6}$ Further study of housing choices is needed to understand the influence of cultural and personal preferences, financial capability and discrimination, and why Māori in particular seldom access these facilities.

\section{Comparison with other populations}

Several NZ or Australian populations are available for comparison. In 2009, Nielsen interviewed 173 village residents in 52 village operations across NZ. They reported to the Retirement Commission that $70 \%$ of village residents were women, and that $73 \%$ were aged 80 years or over. Almost all reported their ethnicity as European (NZ or other). Three-quarters lived alone, and threefifths relied either solely or mostly on income from their 
NZ Superannuation. A third said they had no long-term conditions affecting their health, though $42 \%$ rated their health as fair or poor. Overall, $9 \%$ reported having three or more disabilities around a third had conditions affecting their sight $(39 \%)$ or movement $(32 \%)$.

In 2016, a survey conducted in 240 villages in South Australia conducted, 2154 residents either completed and posted questionnaires or responded online; $48 \%$ were aged over 80 years, $62 \%$ were women. ${ }^{27}$ That $57 \%$ lived alone seems similar to the $56 \%$ of the Auckland volunteers, but a higher proportion, $69 \%$, of sampled respondents, lived alone. Self-rated health was rated as good or better by $75 \%$, with nearly $25 \%$ rating their health as just fair or poor. In terms of assistance for daily living, 57\% said they received no assistance. For those who did receive some sort of assistance, housework was by far the most common activity help was received with, followed by transport.

Nationwide annual monitoring in Australia reports that residents of about 70000 village units were on average aged 81 years of age (though in villages established less than 20 years ago the average age was younger), with $63 \%$

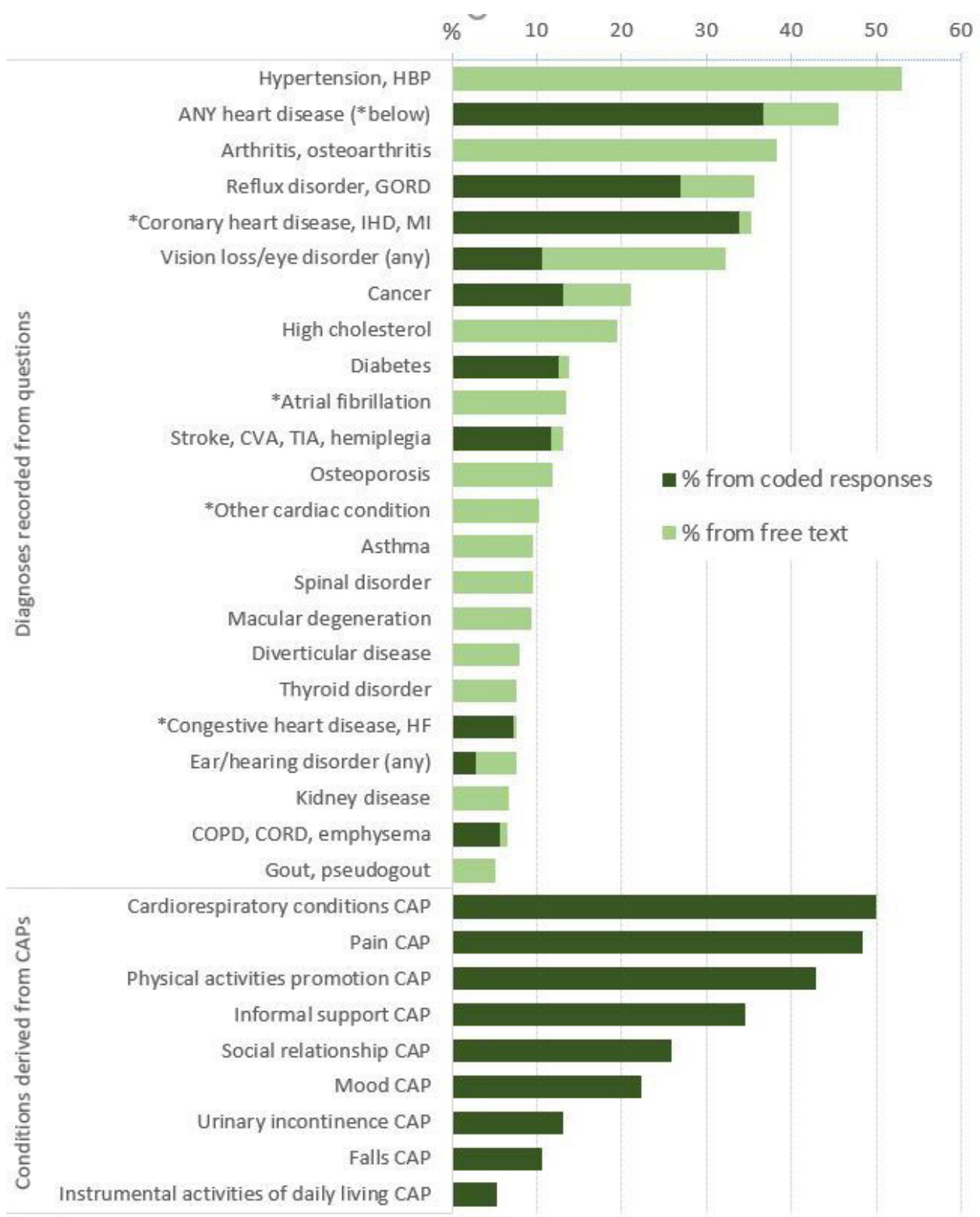

Figure 1 Diagnoses and health needs. 'Any heart disease' is derived from combining all diagnoses in the figure marked with an *. CAP, clinical assessment protocol; COPD, chronic obstructive pulmonary disease; CORD, chronic obstructive respiratory disease; CVA, cerebrovasclar attack; GORD, Gastro-oesophageal reflux disease; HBP, high blood pressure; HF, heart failure; IHD, ischemic heart disease; MI, myocardial infarction; TIA, transient ischaemic attack.i

\footnotetext{
${ }^{\mathrm{i}}$ Abbreviations HBP high blood pressure GORD Gastro-oesophageal reflux disease IHD ischemic heart disease CVA cerebrovasclar attack TIA transient ischaemic attack MI myocardial infarction HF heart failure COPD chronic obstructive pulmonary disease CORD chronic obstructive respiratory disease* signifies that 'Any heart disease' is derived from combining all diagnoses in the figure marked with an *.
} 
women. ${ }^{28}$ Of all units, $32 \%$ were occupied by couples, thus average occupancy was 1.3 people, somewhat more that in the current Auckland study.

Comparison is also possible with all people in NZ having their needs assessed to access supports and services. Schluter and colleagues described 47236 mainly home-dwelling people having an interRAI HC assessment between July 2012 and June $2014 .^{22}$ The residents in the current Auckland study were younger than those assessed for services (33\% vs $43 \%$ aged over 85 years), more likely to identify with European ethnic groups (97\% vs $88 \%$ ), to live alone ( $61 \%$ vs $47 \%$ ) and less likely to selfrate their health as poor/fair (23\% vs $47 \%)$. Further, $4 \%$ of village residents scored 3 or higher on the DRS indicating depression, compared with $18 \%$ of $\mathrm{HC}$ assessments reported in the national interRAI report for 2017-2018. ${ }^{29}$ It is clear that village residents' health overall is better than those with an interRAI record in the community (ie, non-village and non-LTCF settings), though the comparison is perhaps misleading given that national interRAI data include only those seeking assistance whereas many village residents live independently without home help or personal cares.

In comparison to those living in the community and not being needs assessed, in an NZ cohort of non-Māori in the Te Puāwaitanga O Ngā Tapuwae Kia Ora Tonu/Life and Living in Advanced Age, a Cohort Study in New Zealand (LiLACs study), 14\% rated their health as poor/fair, $5 \%$ were current smokers, with a median of five prescribed medications $^{30}$; in comparison, in our village residents aged about 3 years younger, 23\% rated their health as poor/fair, $1 \%$ were current smokers, with a median of five medications per resident. A study of medicationrelated risk factors among residents of RV in Victoria, Australia showed $95 \%$ used prescription medications, with a median of four medications per resident. ${ }^{31}$ The health and dependency of village residents are thus again seen to lie between those living independently and those receiving subsidised home-based supports and services in the community, as previously described in a small preliminary study. ${ }^{9}$

\section{Diagnoses and unmet needs}

Diagnoses most commonly identified were also similar to LiLACs, though their prevalence in our residents was much lower: hypertension (our residents $53 \%$ vs LiLACs $83 \%)$, any cardiovascular disease ( $46 \%$ vs $63 \%)$, coronary artery disease ( $35 \%$ vs $42 \%$ ), eye disease (32\% vs $65 \%) .{ }^{32}$ Lower prevalence among village residents may be because they were on average younger and/or in better health, but may also be because information sources for the LiLACs medical conditions additionally included clinical records (both primary care and hospital databases) rather than rely on self-report, and possibly more thoroughly reported. In LiLACs, fewer participants (26\%) reported pain, but again measurement differed. Almost $50 \%$ of our residents reported ongoing pain (even more were reported in text), justifying attention. This study shows that $71 \%$ of residents had three or more interRAI CAPs triggered; if these unmet needs were addressed, there could be gains to health, quality of life and longevity.

Residents commonly experience many concurrent diagnoses and manage a number of medications, mostly without assistance. The list of diagnoses for our residents differed markedly from all interRAI HC assessments in 2016 where dementia, depression, anxiety, stroke, congestive heart disease and diabetes were much more often recorded. ${ }^{33}$ This is largely because we additionally included diagnoses captured in free text: over $50 \%$ reported hypertension, almost 20\% high cholesterol, with over $10 \%$ reporting atrial fibrillation and osteoporosis, though none of these conditions appear in interRAI reports because they are not asked about specifically. Consideration might be given to include some of these more specifically in the interRAI assessment, especially those contributing to clinical management of chronic symptoms, or, for example, potentially inappropriate prescribing. ${ }^{34}$

That $19 \%$ of residents described themselves as providing daily support for others suggests that investigating the interdependence between those who cohabit may be justified, to inform the need for formal care services should one partner no longer be able to assist.

Many other topics were covered. One is the proportion $(43 \%)$ of residents whose faith in God or spiritual aspects of life influenced how they lived. In the 2013 national census, most people aged $65+$ stated a religious affiliation, with just $20 \%$ saying they had no religion. ${ }^{35}$ Greater faithorientation among residents may have been expected given that several larger villages in the region were originally established by churches that recognised the need for housing growing numbers of older people, and which continue to be occupied by people that share similar values, but this was not apparent. Elsewhere, religious participation is significantly associated with self-perceived health and well-being. ${ }^{36} 37$

\section{Choosing to move into a village}

The decision to move into a village is complex, with consideration given to health, family, financial, cultural and other factors. ${ }^{38} 39$ Residents stated that they anticipated supports and services would be available within the village if/when needed. A NZ-wide survey undertaken in 2006 for the Retirement Commissioner reported that the top three reasons for moving into a village were based around security and peace of mind-for security (55\%), house/garden too much to manage $(49 \%)$ and wanted fewer worries (39\%). ${ }^{6}$ Care and support $(37 \%)$ and pressure from families $(36 \%)$ also played a large part. Our findings align well with findings from the Commissioner's study and others.

\section{Implications}

In an Australian study, Gardner ${ }^{40}$ described two distinct groups of individuals relocating to RV: 'planners' who anticipate future health decline and move before there 
is a clear need, and 'reactors', who experience health problems and then move. ${ }^{40}$ Perhaps that distinction is relevant here, for compared with sampled residents, the volunteers were more likely to have investment income, less often came seeking immediate healthcare assistance or feeling under pressure by family, all indicating anticipation of future needs. Fewer volunteers reported poor quality of life. In contrast, sampled residents were more likely to experience an event(s) that prompted the move to the village or moved for financial reasons. They were less independent and were more likely to defer dental, eye and hearing examinations. These findings seem to align with Gardner's observations, but intriguingly, differences were small between the groups in more objective measures of health (scales and CAPS), in diagnoses, and in overall satisfaction with the village.

If this dichotomy is real, the balance between the two groups of residents will no doubt vary between villages and also over time within any one village, and will impact on the social and recreational lives of residents. Importantly for research, it confirms that the findings a survey gives depends on who is asked. When surveys recruit without attempting a representative sample, important selfselection bias occurs and findings may thus mislead. ${ }^{4142}$ Careful consideration of recruitment methods is needed when interpreting or comparing survey findings. Having said that, to recruit such a sample is challenging, as recognised by Wagner $e t \mathrm{al}^{43}$

In a survey of the RV association members (which does not include all village operators), more than half report that their village offers an on-site residential long-term care facility, while others offer long-term supportive care under contract in apartments in the main building. ${ }^{1}$ The question here though is support with housework, ADLs and personal cares, including occasional nursing services. In a 2006 survey of operators of $\mathrm{NZ}$ villages, $70 \%$ reported they offered some nursing, medical and/or other healthcare. ${ }^{6}$ While it is fair to observe that villages are not primarily set up as care facilities or health service providers, their residents do expect them to offer support services-in the current study 6 in 10 residents said that part of the reason for moving was to access healthcare assistance (either immediately or anticipating future needs). The distinction between expectation and reality was noted in the Retirement Commissioner's report, where the concern most commonly mentioned was that the level of care and support was not as high as expected. ${ }^{6}$ A study in Queensland, Australia also concluded that older people moving to RV expect that in-home caregiving assistance will be available to them or their spouse when required, regardless of any stated management policy, and that villages needed to address this demand. ${ }^{44}$

In an observational cohort study comparing two models of primary care in four different continuing care retirement communities in the USA, integrating primary healthcare into a retirement community lead to fewer hospitalisations. Where an on-site primary care team provided round-the-clock care in that community, resident hospitalisations were 2.0-3.8 times fewer than when physicians who had independent practices outside of the retirement community provided limited on-site primary care and after-hours care. ${ }^{45}$ These findings imply that facilities which provide ongoing primary care cover have potential to reduce the use of off-site urgent care.

In our study, the CAPs commonly triggered showed important levels of unmet health need, most notably for prevention and management of cardiorespiratory disease/risk and pain, and for help to manage chronic diseases. Facilities such as nurse-led clinics (for cardiorespiratory management/support, pain management, risk monitoring, short-stay/overnight sick bay, or advice), physiotherapy, podiatry and exercise programmes might help meet those needs. On-site health services may be more efficient and accessible, and thus more effective, than services dispersed in standard NZ low-density housing. The conglomerate nature of housing in a village setting might thus offer efficiencies in health service provision compared with detached housing settings.

In general, residents were mobile, living independently and engaged in social activities even if receiving formal help or care. Computers were a part of life for many residents, with over half using a computer for email $(70 \%)$ and for health knowledge (52\%). In NZ, a significant positive relationship has been described between internet/ email usage and general well-being, higher self-reported health status, increased participation and leadership in, and increased satisfaction with, leisure and recreation activities. ${ }^{46}$ This was confirmed in a systematic review of 18 quantitative cross-sectional studies, with all but one showing statistically significant correlations for at least one mental health outcome. ${ }^{47}$ Technologies including voice-activated assistants such as Alexa (Amazon) and Siri (Apple) already offer new learning and social connections for residents ${ }^{48}$ and have potential for health monitoring and care coordination. ${ }^{49}$ Further research and development might improve quality of life and social engagement.

\section{Strengths and limitations}

To our knowledge, this study is the largest cross-sectional survey describing social, health and functional needs of village residents in NZ. It has also established a cohort for a longitudinal cohort study of healthcare utilisation and an RCT of a health service intervention. Considerable efforts were made to obtain a representative sample, and although the response rate was low, it was not unusually so for people who are very old. ${ }^{43}$ Village managers, sometimes in consultation with residents, determined the method of recruitment thus a mix of sampled residents and volunteers was included. Randomly sampled participants generally yield more trustworthy results than volunteers because the self-selection component of participation is reduced. ${ }^{50}$ The sampled and volunteer residents were similar demographically and in most measures of health, so the combined results can be reasonably relied on. However, in some social and behavioural measures, 
there were significant differences between sampled residents and volunteers. The findings may therefore not always well represent all village residents in the region. Nevertheless, by recruiting residents from 33 villages, the findings for demographic characteristics and most health measures are likely to be more reliable than studies conducted in a small number of villages or entirely with volunteers. We collected no information about resident occupation/retirement status, numbers or ages of children or siblings.

The survey and needs assessments were conducted by experienced GNSs certified in the use of interRAI and in assessing the health-related needs of older people. If the GNS had any question about a resident's cognitive capacity to consent, participation was precluded, to comply with NZ regulations. Results will therefore slightly overstate measures of capacity.

Use of interRAI has many benefits, mainly that questions are validated and largely standardised internationally. ${ }^{21}{ }^{22}$ However, the interRAI CHA collects only two of the four items needed to derive the ADL short-form scale and therefore the IADL score, unless the Functional Supplement triggers. We therefore imputed the uncollected eating and toilet use items as 'independent'; this overall may have led to slight underestimates of function and dependency. Finally, statistical comparisons of the two groups presented here are unadjusted for possible confounders, while the number of statistical tests may have raised spurious significant findings.

In summary, most village residents report good quality of life; they may access services and supports more easily than non-residents, yet many have high levels of comorbidity with health needs that are unmet. People who move to a village often do so in the expectation that health and support services will be available when needed. High levels of unmet need suggest health services are inadequatecommon cardiorespiratory problems and ongoing pain in particular warrant attention in order to improve quality of life and to delay/avert hospital/ Emergency Department /long-term care presentation. Supports such as on-site nurse-led clinics to help manage chronic conditions and extra short-term care during illness have potential to improve health outcomes for residents. Village operators, tertiary, secondary and primary care providers could cooperate to develop and test appropriate interventions.

\section{Author affiliations \\ ${ }^{1}$ Department of Geriatric Medicine, Faculty of Medical and Health Sciences, University of Auckland, Auckland, New Zealand \\ ${ }^{2}$ Health of Older People, Waitematā District Health Board, Auckland, New Zealand ${ }^{3}$ Department of Pharmacy, University of Auckland, Auckland, New Zealand ${ }^{4}$ Executive Leadership Team, Waitematā District Health Board, Auckland, Auckland, New Zealand \\ ${ }^{5}$ School of Nursing, University of Auckland, Auckland, New Zealand \\ ${ }^{6}$ Auckland District Health Board, Auckland, New Zealand}

Acknowledgements We acknowledge with thanks the village managers who accepted our researchers in, and the residents who kindly responded to our invitation to participate. Our thanks also to Gabrielle Peters for administrative support and to Amanpreet Bhandal, Lydia Siew, Lucy Groenhart, Britany Williams, Jose Manuel Gonzalez, Naomi Kang and Yao He for their contributions to the project.

Contributors MC (principal investigator), MB, DB, JBB, KB and KP were named investigators on the wider project and helped plan the study. For this report, JBB planned and drafted the paper, ZW conducted statistical analyses, MC, KB, JH, $\mathrm{MB}$ and $\mathrm{KP}$ provided clinical expertise. AT and CC interviewed and collected data, A-MH undertook project management, while DB provided support and valuable suggestions. MC provided guidance and oversight. Every author contributed by critically reviewing and revising the manuscript.

Funding This work was supported by two main funders, National Science Challenge Ageing Well (NZ) (UOOX1508, 12815/1, SUB1301) and the Waitematā District Health Board. Support came also from The Hope Foundation, the University of Auckland and Freemasons New Zealand that enabled preparatory work.

Competing interests None declared.

Patient consent for publication Not required.

Ethics approval The New Zealand Health and Disability Ethics Committee (16/ CEN/34) gave ethics approval. Written, informed consent was obtained from all participants.

Provenance and peer review Not commissioned; externally peer reviewed.

Data availability statement Data may be obtained from a third party and are not publicly available from the researchers. When applying for ethics approval, we undertook to protect data confidentiality, and did not obtain participants' approval to share it with others. We will however consider reasonable requests for collaboration, working within those constraints. Under certain conditions, interRAI data are available from TAS (Technical Advisory Services) in Wellington.

Open access This is an open access article distributed in accordance with the Creative Commons Attribution Non Commercial (CC BY-NC 4.0) license, which permits others to distribute, remix, adapt, build upon this work non-commercially, and license their derivative works on different terms, provided the original work is properly cited, appropriate credit is given, any changes made indicated, and the use is non-commercial. See: http://creativecommons.org/licenses/by-nc/4.0/.

ORCID iD

Joanna B Broad http://orcid.org/0000-0003-0157-7031

\section{REFERENCES}

1 Jones Lang LaSalle. New Zealand retirement village database (NZRVD) November 2017. Auckland: Jones Lang LaSalle, 2018.

2 Petersen M, Tilse C, Cockburn T. Living in a retirement village: choice, contracts, and constraints. J Hous Elderly 2017;31:229-42.

3 Malta S, Williams SB, Batchelor FA. 'An ant against an elephant': retirement village residents' experiences of disputes and dispute resolution. Australas J Ageing 2018;37:202-9.

4 Glass AP, Skinner J. Retirement communities: we know what they are ... or do we? J Hous Elderly 2013;27:61-88.

5 Bäumker T, Callaghan L, Darton R, et al. Deciding to move into extra care housing: residents' views. Ageing Soc 2012;32:1215-45.

6 ACNielsen. Retirement villages survey 2006. Wellington: Retirement Commission, 2006.

7 Croucher K. Making the case for retirement villages. Joseph Rowntree Foundation: York, 2006.

8 Holland C, Boukouvalas A, Wallis S, et al. Transition from community dwelling to retirement village in older adults: cognitive functioning and psychological health outcomes. Ageing Soc 2017;37:1499-526.

9 Bhandal AK, Siew L, Broad JB, et al. Feasibility study to describe the dependency levels of people living in retirement villages in Auckland. New Zealand [Abstract] Australas J Ageing 2012;31:59-60.

10 Jones Lang LaSalle. New Zealand retirement village database (NZRVD) May 2014. Auckland: Jones Lang LaSalle, 2015.

11 Jones Lang LaSalle. New Zealand retirement village database (NZRVD) May 2015. Auckland: Jones Lang LaSalle, 2016.

12 Jones Lang LaSalle. New Zealand retirement village database (NZRVD) November 2016. Auckland: Jones Lang LaSalle, 2017

13 Jones Lang LaSalle. New Zealand retirement village database (NZRVD) May 2019. Auckland: Jones Lang LaSalle, 2019.

14 Losekoot E, Theresa Z. Retirement villages: hospitals or hospitality operations - management attributes and traits. $J$ Hosp Tour Manag 2018;34:75-81.

15 Dodds A. Old age, retirement villages and New Zealand Society: a critical narrative analysis of the experiences of retirement village residents. Albany: Massey University, 2018. 
16 Yeung P, Good G, O'Donoghue K, et al. What matters most to people in retirement villages and their transition to residential aged care. Aotearoa N Z Soc Wor 2017;29:84-96.

17 Kingston P, Bernard M, Biggs S, et al. Assessing the health impact of age-specific housing. Health Soc Care Community 2001;9:228-34

18 Bekhet AK, Zauszniewski JA, Nakhla WE. Reasons for relocation to retirement communities: a qualitative study. West J Nurs Res 2009;31:462-79.

19 Peri K, Broad JB, Hikaka J, et al. Study protocol: older people in retirement villages. A survey and randomised trial of a multidisciplinary invention designed to avoid adverse outcomes. BMC Geriatr 2020;20:247.

20 New Zealand Government. Health and disability commissioner (code of health and disability services consumers' rights regulations). Wellington: New Zealand Government, 1996.

21 Hirdes JP, Ljunggren G, Morris JN, et al. Reliability of the interRAI suite of assessment instruments: a 12-country study of an integrated health information system. BMC Health Serv Res 2008;8:277.

22 Schluter PJ, Ahuriri-Driscoll A, Anderson TJ, et al. Comprehensive clinical assessment of home-based older persons within New Zealand: an epidemiological profile of a national cross-section. Aust N Z J Public Health 2016;40:349-55.

23 Morris J, Berg K, Björkgren M, et al. interRAl community health (CHA) assessment form and user's manual and related materials. Washington DC: interRAl, 2010.

24 Morris JN, Berg K, Fries BE, et al. Scaling functional status within the interRAI suite of assessment instruments. BMC Geriatr 2013;13:128.

25 Morris J, Berg K, Björkgren M, et al. interRAl clinical assessment protocols (CAPs) for use with community and long-term care assessment instruments. Washington DC: interRAI, 2010.

26 Boyd M, Calvert C, Tatton A, et al. Lonely in a crowd: loneliness in New Zealand retirement village residents. Int Psychogeriatr 2020:1-13.

27 McDougall K, Barrie H. South Australia retirement village survey 2016. Adelaide: SA Health Office for the Ageing, South Australia, 2017.

28 PwC Australia, Property Council of Australia. 2019 PwC/Property Council retirement census. Sydney: Property Council, 2019. https:// research.propertycouncil.com.au/research-and-data?sector= Retirement+Living\&state $=2020$

29 Technical Advisory Services. Annual report 2017/18. Wellington: Technical Advisory Services, 2018.

30 Kerse N, Teh R, Moyes SA, et al. Socioeconomic correlates of quality of life for non-Māori in advanced age: te Puāwaitanga O NGA Tapuwae Kia ora Tonu. life and living in advanced age: a cohort study in New Zealand (LiLACS NZ). N Z Med J 2016;129:18-32.

31 Lee CY, George J, Elliott RA, et al. Prevalence of medication-related risk factors among retirement village residents: a cross-sectional survey. Age Ageing 2010;39:581-7.

32 Teh R, Kerse N, Kepa M, et al. Self-rated health, health-related behaviours and medical conditions of Maori and non-Maori in advanced age: LiLACS NZ. N Z Med J 2014;127:13-29.
33 Technical Advisory Services. Annual report 2016/17. Wellington: Technical Advisory Services, 2018.

34 Thomas RE, Thomas BC. A systematic review of studies of the STOPP/START 2015 and American geriatric Society beers 2015 criteria in patients $\geq 65$ years. Curr Aging Sci 2019;12:121-54

35 Statistics New Zealand. QuickStats about people aged 65 and over, 2015. Available: https://www.stats.govt.nz/

36 Wilmoth JD, Adams-Price CE, Turner JJ, et al. Examining social connections as a link between religious participation and well-being among older adults. J Relig Spiritual Aging 2014;26:259-78.

37 Yohannes AM, Koenig HG, Baldwin RC, et al. Health behaviour, depression and religiosity in older patients admitted to intermediate care. Int J Geriatr Psychiatry 2008;23:735-40.

38 Omoto AM, Aldrich CD. Retirement community life: issues, challenges, and Opportunities1. Annu Rev Gerontol Geriatr 2006;26:283

39 Roy N, Dubé R, Després C, et al. Choosing between staying at home or moving: a systematic review of factors influencing housing decisions among frail older adults. PLoS One 2018;13:ARTN e0189266.

40 Gardner IL. Why people move to retirement villages: home owners and non-home owners. Aust J Ageing 1994;13:36-40.

41 Kelfve S, Lennartsson C, Agahi N, et al. Do postal health surveys capture morbidity and mortality in respondents aged 65 years and older? A register-based validation study. Scand J Public Health 2015;43:348-55.

42 Lohr S. Sampling: design and analysis. Pacific Grova, CA: Duxbury Press, 1999.

43 Wagner M, Kuppler M, Rietz C, et al. Correction to: non-response in surveys of very old people. Eur J Ageing 2019;16:131-2.

44 Buys LR. Care and support assistance provided in retirement villages: expectations vs reality. Australas J Ageing 2000;19:149-51.

45 Bynum JPW, Andrews A, Sharp S, et al. Fewer hospitalizations result when primary care is highly integrated into a continuing care retirement community. Health Aff 2011;30:975-84.

46 Koopman-Boyden PG, Reid SL. Internet/e-mail usage and well-being among 65-84 year olds in New Zealand: policy implications. Educ Gerontol 2009;35:990-1007.

47 Forsman AK, Nordmyr J. Psychosocial links between internet use and mental health in later life: a systematic review of quantitative and qualitative evidence. J App/ Gerontol 2017;36:1471-518.

48 Pedrozo Campos Antunes T, Souza Bulle de Oliveira A, Hudec R, et al. Assistive technology for communication of older adults: a systematic review. Aging Ment Health 2019;23:417-27.

49 Khosravi P, Ghapanchi AH. Investigating the effectiveness of technologies applied to assist seniors: a systematic literature review. Int J Med Inform 2016;85:17-26.

50 Wolf C, Joye D, Smith TW, et al. The SAGE Handbook of survey methodology. London: Sage Publications, 2016. 